\title{
Migraine without aura in academics of physical therapy course
}

\author{
Élcio Alves Guimarães', Bárbara Martins Rodrigues², Kelly Duarte Lima Makhoul33, Lucas Resende Sousa4, Paulo Cézar \\ Simamoto Junior ${ }^{5}$, Gilmar da Cunha Sousa ${ }^{6}$, Alfredo Júlio Fernandes Neto ${ }^{5}$
}

\begin{abstract}
Introduction: Migraine is a primary headache that is usually severe. It is classified into five main categories, the two most important being migraine without aura and migraine with aura. The common, without aura, is characterized by periodic headaches that are usually pulsatile and unilateral, exacerbated by activities and associated with nausea, photophobia and phonophobia. In academics, headaches lead to loss of days of study and worse academic performance. Objective: The objective of this study was to evaluate the prevalence of migraine without aura in academics of the Physiotherapy course. Methodology: A total of 217 physiotherapy students over 18 years of age were evaluated, and the headache questionnaire was applied according to the International Classification of Headache Disorders, 3rd edition, 2014. Conclusion: It is concluded that there was prevalence of migraine without aura in academics of the Physiotherapy course.

Keywords: Academics; International Classification of Headache Disorders; Migraine without aura.
\end{abstract}

\section{INTRODUCTION}

According to the World Health Organization, headache is the second most common complaint of pain. ${ }^{(1)}$ It is estimated that more than half of the world's population has some kind of headache in some stage of theirs life. ${ }^{(2)}$ Among the general population, headaches are highly prevalent and receive increasing attention, not only because they affect the quality of life of people, but also because they have a significant economic impact. ${ }^{(3)}$

Primary headache is characterized by the absence of anatomopathological abnormalities and is not due to specific organic diseases of intracranial or systemic origin. Headaches include migraine with or without aura, tension-type headache, cluster headache, trigeminal-autonomic cephalgias (including paroxysmal hemicranias), and various headaches not associated with structural injury. ${ }^{(2)}$ Progress in headache research has been benefited because of the International Classification of Headache Disorders (ICHD) and its revisions, as they provided operational diagnostic criteria that allow better comparison of clinical data between headache centers. ${ }^{(3)}$

Migraine is a common and disabling primary headache disorder. ${ }^{(4)}$ It is unilateral and pulsatile by nature and often accompanied by phono or photophobia, nausea, vomiting and worsens with physical activity. A number of external and internal factors are considered triggers for migraine. Among them, the most common are stress, dietary factors, environmental factors, hormonal factors and sleep disorders. ${ }^{(5)}$
The most frequent headaches in the population, in general, are migraine and tension-type headaches. ${ }^{(2)}$ Headache is underdiagnosed and undertreated in certain populations, such as undergraduate students. In this specific population, headaches lead to loss of days of study and worse academic performance. Few studies were conducted on undergraduate students. Bigal et al. ${ }^{(6)}$, found a prevalence of $25 \%$ of migraine in Brazil and they also observed that the students with migraine showed a decrease of $62,7 \%$ in productivity in comparison with a decrease of $24,4 \%$ in the ones with episodic tensiontype headache. ${ }^{(7)}$

Migraine has a significant impact on the quality of life, the health resources, and the professional and personal activities of patients. ${ }^{\left({ }^{8}\right)}$ Some studies on the prevalence of migraine have reported that migraine may be more common in college students than in other social groups. ${ }^{(9)}$

Migraine is classified into five major categories, the two most important of which are: migraine without aura and migraine with aura. The classic, with aura, exhibits temporary neurological symptoms consisting of sensory, motor or cognitive dysfunctions, which usually precede headache or appear during or after access. ${ }^{(10)}$

Criteria for migraine without aura are brought together by various combinations of characteristics. At least two of the following pain characteristics must be present when the pain is at worst: natural throbbing; unilateral or more severe

Corresponding author: Name: Élcio Alves Guimarães. Address: Avenida Dos Vinhedos, 900, Bairro Morada da Colina, Uberlândia, MG, Brazil, CEP:38411-159. 
in one side than the other; aggravated by movements or physical activity; of moderate or severe intensity. In addition, at least one of the following combinations of associated symptoms is required: phono and photophobia; nausea or vomiting. It is noted that the unilateral pulsating headache satisfies the criteria, but therefore becomes bilateral, pressing the headache if it is moderate or severe in intensity and aggravated by routine physical activities. With regard to associated features, a patient without nausea or vomiting but with both photophobia and phonophobia may meet the criteria. ${ }^{(6)}$

The headache questionnaire was developed by professionals of Headache and of the University's Outpatient Center of the "Faculdade de Medicina de Ribeirão Preto". The questions were developed to allow classification of headaches according to the criteria of the International Classification of Headache (Headache Classification Subcommittee of the International Headache Society). ${ }^{(11)}$

The objective of the present study was to evaluate the prevalence of migraine without aura in academic students of the Physiotherapy course, through the headache questionnaire.

\section{METHODS}

A field research was proposed with the undergraduate students of the Physiotherapy course of the "Centro Universitário do Triângulo-UNITRI", both females and males over 18 years of age, which was determined the prevalence of migraine without aura, only from September to October 2015.

Data collection was carried out in the classroom with the prior authorization of the course manager and the teacher present in the room, the student who was interested received the free and informed consent form and the data were collected through the application of the International Classification of Headache Questionnaire with 26 objective questions.

Were excluded from the sample students who were not found in the classroom during the data collection period, did not sign the informed consent form and were not properly enrolled in the Physiotherapy course.

After the questionnaire was applied, data were tabulated for screening of the answers by recording at least five episodes meeting these criteria: Headache episodes lasting 4 to 72 hours (untreated or treated successfully). Headache has at least two of the following four characteristics: unilateral, pulsatile, moderate or severe pain, worsening by routine physical activity or its avoidance (e.g. walking or climbing stairs). And during headache, at least one of the following: nausea and/or vomiting, phono and photophobia, being characterized according to the International Classification of Headache Disorders $-3^{\text {rd }}$ edition $-2014 .^{(4)}$

\section{RESULTS}

A total of 217 students of Physiotherapy, both male and female over 18 years of age participated in this study, and the prevalence of migraine without aura was analyzed. Only 10 students $(21.7 \%)$ presented specific criteria for this type of migraine, all female, aged between 18 and 30 years, with a mean of 21 years and 11 months and a standard deviation of 3 years and 8 months.

The diagnostic criteria for migraine without aura used in this study had as reference the third edition of the International Classification of Headache Disorders. ${ }^{(4)}$ This research established the diagnosis of migraine without aura through the headache questionnaire and not through clinical examination.

According to the results found in table 1, were found differences between answers "lasting from 4 to 24 hours" and only one response for the duration of " 1 to 3 days".

The results found in table 2 showed that the answers were variable and the question 'In the two sides of the head' presented the highest frequency.

The results found in table 3 showed that the answers were variable and the question 'Throbbing, pulsatile, like a beating heart' presented the highest frequency.

According to the results found in table 4 the answers were variable and the question '08' presented the highest frequency.

According to the results found in table 5, higher frequencies were found for the 'Aggravates' answer and only one answer was found for the 'Do not aggravate' question and an unanswered question.

According to the results found in table 6 , there were quite variable differences due to several symptom options, being the 'The noise bothers' answer the higher frequency.

Table 1. Frequencies and percentages of answers issued by patients with respect to the question "How long does your headache last if you do not take analgesic?".

\begin{tabular}{lcc}
\hline \multicolumn{1}{c}{ Answers } & Frequencies & Percentages \\
\hline From 1 to 3 days & 01 & $10 \%$ \\
From 4 to 24 hours & 09 & $90 \%$ \\
Total & 10 & $100 \%$ \\
\hline
\end{tabular}

Table 2. Frequencies and percentages of answers issued by patients with respect to the question "Where in the head often hurts?".

\begin{tabular}{lcc}
\multicolumn{1}{c}{ Answers } & Frequencies & Percentages \\
\hline Only on one side of the head & 02 & $20 \%$ \\
Only on one side of the head - Nape & 01 & $10 \%$ \\
On one side of the head, on both sides & 01 & $10 \%$ \\
On the Nape & 01 & $10 \%$ \\
On both sides of the head & 03 & $30 \%$ \\
On the whole head & 02 & $20 \%$ \\
Total & 10 & $100 \%$ \\
\hline
\end{tabular}


Table 3. Frequencies and percentages of answers issued by patients with respect to the question "What is the type of your headache?".

\begin{tabular}{lcc}
\multicolumn{1}{c}{ Answers } & Frequencies & Percentages \\
\hline Throbbing, pulsatile, like a beating heart & 04 & $40 \%$ \\
$\begin{array}{l}\text { Throbbing, pulsatile, like a beating heart, } \\
\text { pressure }\end{array}$ & 01 & $10 \%$ \\
Sharp pinching pains & 03 & $30 \%$ \\
Like a shock, pressure like a head grip & 01 & $10 \%$ \\
Like a weight on top of the head & 01 & $10 \%$ \\
Total & 12 & $100 \%$ \\
\hline
\end{tabular}

Ps: Frequencies exceed the number of patients because many of them have issued more than one answer.

Table 4. Frequencies and percentages of answers issued by patients with respect to the question "from 0 to 10 , being 0 the absence of pain and 10 the strongest pain, what is the intensity of your headache?"

\begin{tabular}{ccc}
\hline Answers & Frequencies & Percentages \\
\hline 03 & 01 & $10 \%$ \\
05 & 02 & $20 \%$ \\
06 & 02 & $20 \%$ \\
07 & 01 & $10 \%$ \\
08 & 04 & $40 \%$ \\
Total & 10 & $100 \%$ \\
\hline
\end{tabular}

Table 5. Frequencies and percentages of answers issued by patients with respect to the question "When you are in pain, physical exertion (climbing stairs, picking up weight, walking fast, doing housework) aggravates the pain or not?".

\begin{tabular}{lcc}
\hline \multicolumn{1}{c}{ Answers } & Frequencies & Percentages \\
\hline Aggravates & 08 & $80 \%$ \\
Do not aggravates & 01 & $10 \%$ \\
Unanswered & 01 & $10 \%$ \\
Total & 10 & $100 \%$ \\
\hline
\end{tabular}

Table 6. Frequencies and percentages of answers issued by patients with respect to the question "Do you have the following symptoms when you have a headache?".

\begin{tabular}{lcc}
\multicolumn{1}{c}{ Answers } & Frequencies & Percentages \\
\hline Seasickness & 05 & $18,52 \%$ \\
You vomit & 03 & $11,11 \%$ \\
The light bothers & 07 & $25,93 \%$ \\
The noise bothers & 08 & $29,64 \%$ \\
The eye turns red & 01 & $3,70 \%$ \\
The eye becomes swollen & 01 & $3,70 \%$ \\
Watery eye & 01 & $3,70 \%$ \\
The eyelid falls & 01 & $3,70 \%$ \\
Total & 27 & $100 \%$ \\
\hline
\end{tabular}

Ps: Frequencies exceed the number of patients because many of them have issued more than one answer.

\section{DISCUSSION}

In a study by Ferri-Debarros et al. was used the second edition of the International Classification of Headache to make the differential diagnosis between migraine and tension-type headache in students of Medicine of the "Universidade de Taubaté". (12) The results showed a prevalence of $22 \%$ for migraine, but the main subtypes of migraine were not differentiated, such as: with or without aura. Demonstrating that these results corroborate with the present study, in which a prevalence of $21 \%$ for migraine without aura was found in the academics of the Physiotherapy course. Galvez et al., in Lima (Peru), classified the definitions of migraine according to the International Headache Society, differentiating between migraine without and with aura. Of the students of Medicine evaluated, 60,8\% presented migraine without aura showing a higher prevalence than the present study. ${ }^{(9)}$

Adoukonou et al. made a study using the criteria of the International Headache Classification of 2004 for classification of migraine, being also differentiated the migraine without aura and with aura. They obtained, as a result, a percentage of $40,9 \%$ of migraine without in academics of several courses in Parakou (Benin), being more elevated than the present study. The authors justify the value found for the cultural reasons, the triggering factors and the methods of study. ${ }^{(13)}$ Andrade et al. classified medical students as having or not having migraine. Representing for students with migraine, a result of $8,6 \%$, being a lower prevalence of migraine than the present study. The authors justified the low prevalence by the young population of the sample that still has a chance to develop this disease during the life. ${ }^{(14)}$ Falavigna et al. used the second edition of the International Classification of Headache to classification of migraine. Students of several courses were selected, of whom, 813 presented headache, being for migraine a prevalence of $6,9 \%$, and inferior when compared to other studies. ${ }^{(7)}$

Regarding the duration of the migraine crisis, which is characterized for migraine without aura from 4 to 72 hours, it occurred in $90 \%$ of " 4 to 24 hours" and $10 \%$ of " 1 to 3 days" in academics of this study (Table 1), corroborating with the results of Andrade et al. who demonstrated that this characteristic occurred in $100 \%$ of medical students in the city of Barbacena. ${ }^{(14)}$ Different of Adoukonou et al. who in the city of Parakou (West Africa) demonstrated that university students presented $62 \%$ of this characteristic for migraine without and with aura, and the two migraines were not separated as to the duration of the crisis. ${ }^{(13)}$

The prevalence of the type of pain (throbbing/pulsatile) was evidenced in $40 \%$ of the academics in this study (Table 3 ), different from the study of Galvez et al. that showed $77,3 \%$ of throbbing/pulsatile pain in medical students with migraine without aura in a university of Lima (Peru), being greater than this study. ${ }^{(9)}$ Andrade et al. showed a prevalence of $60,6 \%$ 
in the students with migraine, being also greater than the present study. ${ }^{(14)}$

The intensity of pain was reported in the questionnaire in a scale from 0 to 10 , being " 0 to 3 ": light, " 3 to 6 ": moderate and "7 to 10 ": severe, taking into account only moderate to severe as a characteristic of migraine, being demonstrated (item 8: severe pain) in $40 \%$ of the academics of this study (Table 4). As Galvez et al. in Peru, also characterized the pain intensity in moderate and severe demonstrating 3,8\% for the severe item in the medical students who presented migraine without aura, being less than the present study. ${ }^{(9)}$ However Andrade et al. in Brazil, characterized the intensity in moderate and strong / intense, being observed in $100 \%$ of medical students, with migraine and without migraine. ${ }^{(14)}$ And Adoukonou et al. also demonstrated a higher result than the current study, confirming $61,4 \%$ of pain intensity for the severe item, in students with migraine from a University in Parakou. ${ }^{(13)}$

The symptoms of migraine were observed: photophobia (light bothers) with percentage of $25,93 \%$ and phonophobia (noise bothers) with percentage of $29,64 \%$, being the main symptoms of migraine (Table 6 ). In a study of Andrade et al. was demonstrated that the percentage of phono and photophobia was of $60 \%$ in medical students with and without migraine. ${ }^{(14)}$ However Galvez et al. demonstrated 15,9\% for photophobia and $0 \%$ for phonophobia in medical students with migraine without aura, not corroborating with the present study. ${ }^{(9)}$

\section{CONCLUSION}

It is concluded that there was a prevalence of migraine without aura in students of the Physiotherapy course of the "Centro Universtário do Triângulo".

\section{AUTHOR'S CONTRIBUTIONS}

All the authors worked actively for the article, participating in all the phases. This article is linked to the Doctoral project in Dentistry - FOUFU of the EAG, doctoral student. BMR participated as an undergraduate student and did the completion of coursework from this article. The Master Professor KDLM was advisor in the completion coursework of the student. The PhD Professors PCSJ, GCS and AJFN are advisors of the EAG. The whole group works cohesively and dynamically.

\section{CONFLICT OF INTEREST}

There was no conflict of interest.

\section{AUTHOR DETAILS}

2Physiotherapist, Centro Universitário do Triangulo (Unitri) , Uberlândia (MG), Brazil.
${ }^{3}$ Physiotherapist, Professor, Centro Universitário do Triangulo (Unitri), Uberlândia (MG), Brazil.

${ }^{4}$ Physiotherapist, Master in Health Science, Universidade Federal de Uberlândia (UFU), Uberlândia (MG), Brazil.

${ }^{5}$ Professor, Faculdade de Odontologia, Universidade Federal de Uberlândia (UFU) , Uberlândia (MG), Brazil.

${ }^{6}$ Professor, Instituto de Ciências Biomédicas, Universidade Federal de Uberlândia (UFU), Uberlândia (MG), Brazil

\section{REFERENCES}

1- Organização Mundial de Saúde (2006). Disponível em: http://www.who. int/mediacentre/factsheets/fs277/en/.

2- Correia LL, Linhares MBM. Enxaqueca e Estresse em Mulheres no Contexto da Atenção Primária. Psic.: Teor. E Pesq. 2014;30(2): 145-152.

3- Coppola G, Lorenzo CD, Schoenen J, Pierelli F. Habituation and sensitization in primary headaches. J Headache Pain. 2013;14(1):65.

4- Classificação Internacional de Cefaleias (ICHD 3). 3edição; 2014.

5- Contantinides V, Anagnostou E, Bougea A, Paraskevas G, Kapaki E, Evdokimidis I, et al. Migraine and tension-type headache triggers in a Greek population. Arq Neuropsiquiatr. 2015 Aug;73(8):665-9.

6- Bigal ME, Kurth T, Hu H, Santanello N, Lipton RB. Migraine and cardiovascular disease: Possible mechanisms of interaction. Neurology. 2009;72(21):1864-1871.

7- Falavigna A, Teles AR, Velho MC, Vedana VM, Silva RCD, Mazzocchin $T$, et al. Prevalence and impact of headache in undergraduate students in Southern Brazil. Arq Neuropsiquiatr 2010;68(6):873-877

8- Lima AMD, Sapienza GB, Giraud VDO, Fragoso YD. Odors as triggering and worsening factors for migraine in men. Arq Neuropsiquiatr 2011;69(2B):324-327

9- Galvez AD, Situ M, Tapia HA, Guillén D, Samalvides F. Prevalencia de migraña en estudiantes de Medicina de una universidad de Lima- Perú. Rev Neuropsiquiatr 2011;74(4):287.

10- Fortes RCS, Vicente JS, Lanzetta BP. O impacto da tontura na qualidade de vida de indivíduos com migrânea. Rev. soc. bras. fonoaudiol. 2010;15(4):520-525.

11- Stuginski-Barbosa J, Speciali JG. Frequency of headache among the employees of a rubber company in the state of São Paulo, Brazil. Sao Paulo Med. J. [Internet]. 2011;129(2):66-72.

12- Ferrl-De-Barros JE, Alencar MJD, Berchielli LF, Junior LCC. Headache among medical and psychology students. Arq Neuropsiquiatr 2011;69(3):502-508

13- Adoukonou T, Tognon-Tchegnonsi F, Philomène $K$, Alabi $A$, Houinato $D$, Preux PM. Prevalence of migraine among university students at Parakou, Benin: A cross-sectional study. World Journal of Neuroscience. 2014;4:1824

14- Andrade AFB, Back DFFT, Rocha EF, Duarte GF, Batista IDCB, Jurno ME, et al. Prevalência e fatores associados à enxaqueca nos estudantes da Faculdade de Medicina de Barbacena, MG - Brasil. Rev Med Minas Gerais 2011; 21(1): 25-31 